\title{
Volumetric PIV measurement for capturing the port flow characteristics within annular gas turbine combustors
}

\author{
Mark A. Brend ${ }^{1} \cdot$ Paul A. Denman ${ }^{1}$. Jon F. Carrotte ${ }^{1}$
}

Received: 3 October 2019 / Revised: 25 February 2020 / Accepted: 6 March 2020 / Published online: 25 March 2020

(c) The Author(s) 2020

\begin{abstract}
The three-dimensional flows within a full featured, unmodified annular gas turbine combustor have been investigated using a scanned stereoscopic PIV measurement technique. Volumetric measurements have been achieved by rigidly translating a stereoscopic PIV system to scan measurements around the combustor, permitting reconstruction of volumetric single-point statistics. Delivering the measurements in this way allows the measurement of larger volumes than are accessible using techniques relying upon high depth of field imaging. The shallow depth of field achieved in the stereoscopic configuration furthermore permits measurements in close proximity to highly detailed geometry. The measurements performed have then been used to assess the performance of the combustor port flows, which are central to the emissions performance and temperature/velocity profile at turbine inlet. Substantially differing performance was observed in the primary ports with circumferential position, which was found to influence the behaviour of the second secondary port jets. The measurements indicated that the interaction between the primary and secondary jets occurred due to variations in the external boundary conditions imposed by the annular passages in which the combustor is located.
\end{abstract}

Mark A. Brend

m.brend@lboro.ac.uk

1 National Centre for Combustion and Aerothermal

Technology, Loughborough University,

Loughborough LE11 3GR, UK 


\section{Graphic abstract}

Scanned PIV delivery system

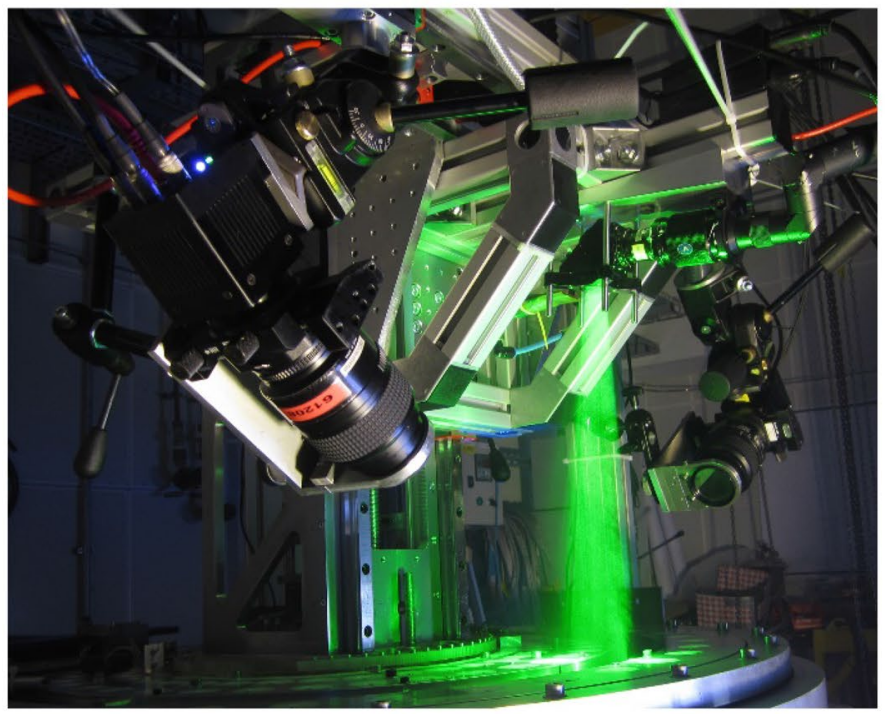

Measured planar data

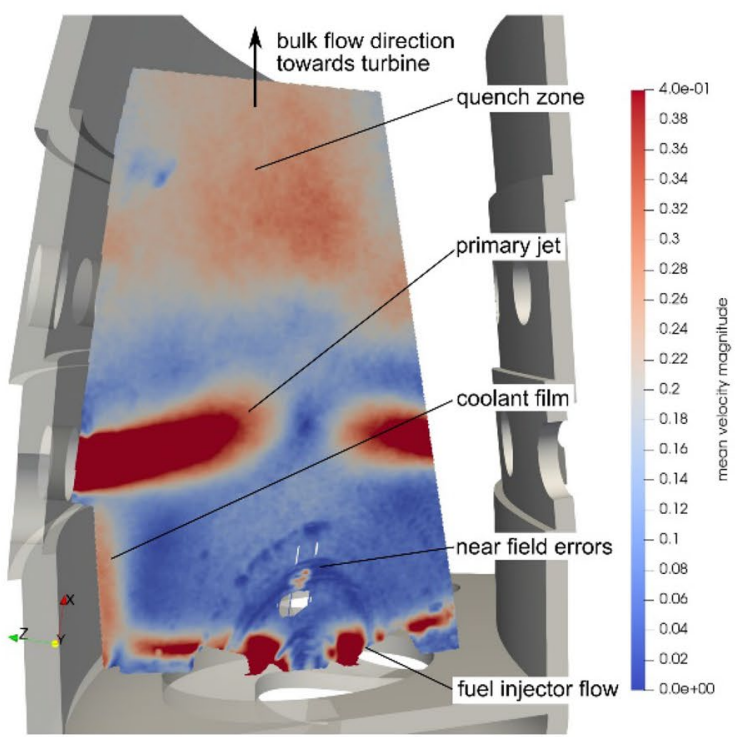

Streamline tracing showing interactions of primary and secondary port jets, with contours of TKE ( 85 th percentile)

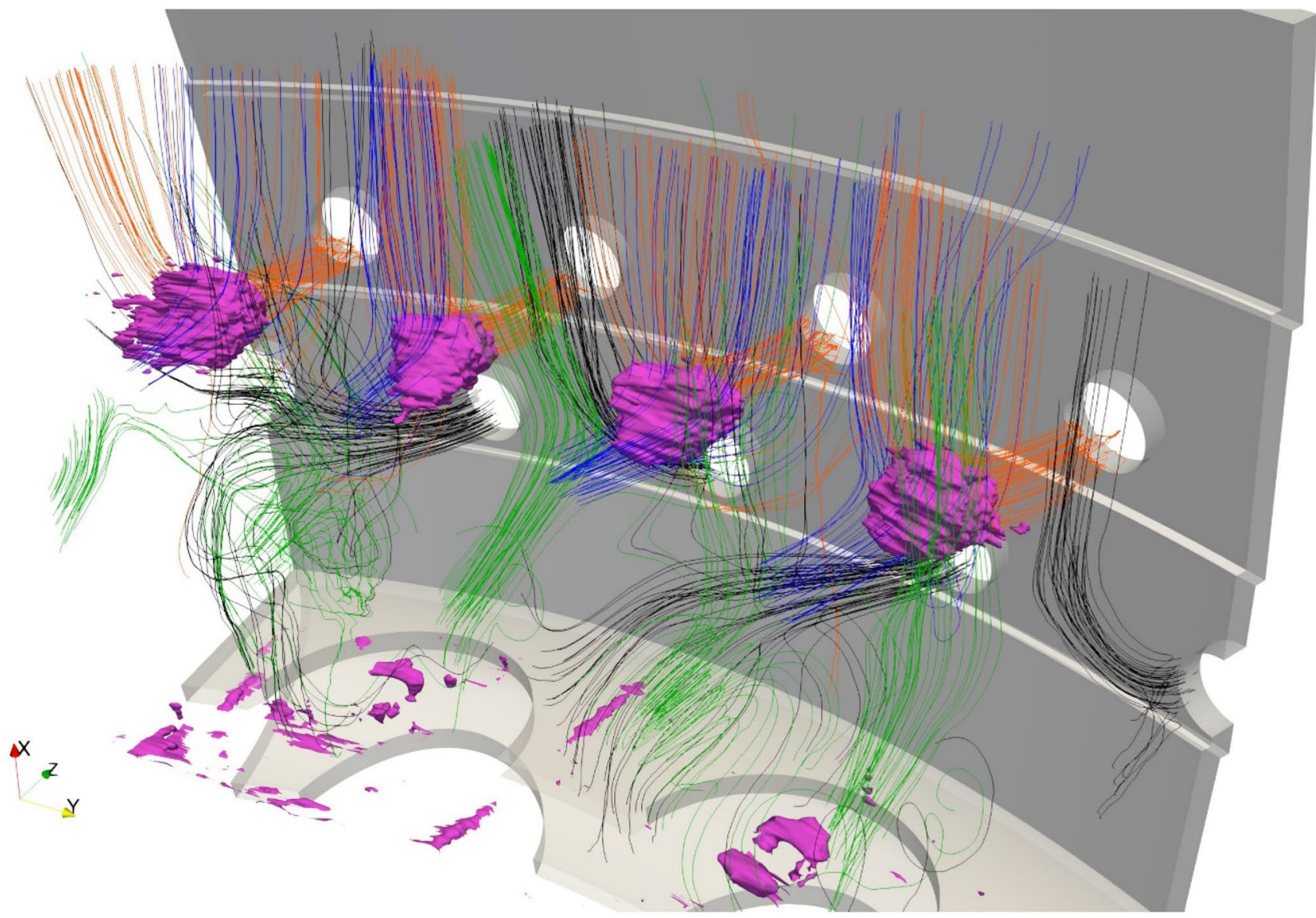




\section{Introduction}

This work demonstrates a novel approach for measuring volumetric velocity field data by rigidly translating a calibrated stereoscopic PIV system. The measurement system has been demonstrated by performing a survey of the velocity field within an annular gas turbine combustor, operating in an unfuelled condition. The tests were performed on the isothermal, low-speed, fully annular test facilities at Loughborough University, UK, which carefully manage the total pressure field surrounding the combustion system. The design of the facility is such that the aerodynamic boundary conditions generated are scaled from engine operation (Wray et al. 1993; Denman 2002).

Because of the annular shape of a modern combustor, optical access without geometric modifications is challenging. Laser delivery and imaging were therefore performed through the combustor nozzle. In the engine, the nozzle is used to accelerate gas into the turbine, but on the annular facility, the nozzle instead exhausts into a plenum formed by the test cell. For the combustor geometry tested, the nozzle restricts possible views upstream, into the primary zone. Reasonably, a maximum of two views may be achieved, prohibiting conventional volumetric measurement techniques (e.g. PTV or tomographic PIV).

Volumetric PIV data have therefore been acquired using a scanned approach. This is loosely derived from the technique pioneered by Brücker (1997), where the laser sheet was scanned sufficiently fast to eliminate flow changes between scan locations. For this study, the PIV system was scanned slowly across multiple spatial locations with large numbers of samples acquired at each position. This approach permits the calculation of time domain, volumetric statistics, but precludes the calculation of two-point statistics, e.g. turbulence length scales. The scanned approach developed is broadly similar to the work of Timmerman et al. (2009) and more recently Schroll et al. (2017), who scanned two component PIV measurements in order to build statistics and reconstruct three component vector data.

The measurements described here, however, scan the PIV system at resolution of the order of the light sheet thickness. This permits straightforward reconstruction of threedimensional, three component (3D3C) velocity statistics. To the authors knowledge, this is the first application of a scanned stereoscopic system performing volumetric velocity measurements on highly detailed geometry. Demonstrating the application of this technique is therefore the primary aim of this work.

The velocity field generated within a modern rich-quench-lean (RQL) combustor operating under unfuelled, non-reacting conditions has therefore been surveyed.
3D3C measurements of unmodified, fully featured, annular combustors are not commonly reported in the literature, due to the high level of measurement complexity. The design of an RQL combustion system has therefore been discussed as background to the measurements presented. The fully annular test facility on which measurements have been performed and the details of the developed PIV measurement system have then been described, with the measurement uncertainty quantified. Semi-quantitative results are presented, describing the bulk mass transport processes associated with the isothermal the port flows.

\section{Background}

The RQL system has provided a viable means of reducing the emissions of oxides of nitrogen $\left(\mathrm{NO}_{x}\right)$ by thermal management of the gases within the combustion chamber. $\mathrm{NO}_{x}$ emissions are central to engine performance, as thermodynamic efficiency gains may be sought by increasing engine core temperatures. Because NO production rates scale exponentially with temperature (Lefebvre and Ballal 2010), higher core temperatures result in higher $\mathrm{NO}_{x}$ emissions.

RQL combustor designs deliver this thermal control using equivalence ratio management. The reacting mixture is transitioned from rich to lean using a fast "quench" process (Feitelberg et al. 1998; McKinney et al. 2007; Samuelsen et al. 2013), illustrated in Fig. 1. A rich primary zone is formed of air passing through the fuel injector and primary ports. By depleting oxygen, reaction progress and so heat release is slowed, leading to reduced flame temperatures and therefore NO production. A side effect of the rich mixture is incomplete combustion, which decreases efficiency and increases the emission of pollutants such as carbon

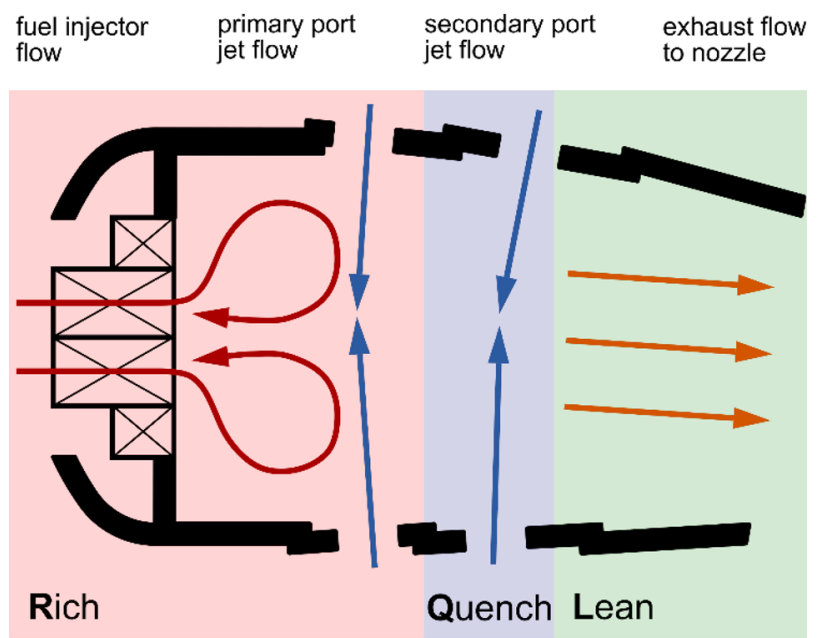

Fig. 1 An illustration of the reacting gas paths within a typical annular rich-quench-lean combustion system 
monoxide and hydrocarbons. Secondary ports add further coolant, decreasing the temperature of the combustion products and forming a reacting mixture with lean equivalence ratio. The final lean combustion process aims to complete the conversion of the fuel into combustion products, e.g. water and carbon dioxide.

In performing the rich to lean transition, stoichiometric equivalence ratios cannot be entirely avoided. Locally, fluid regions are expected to reach stoichiometric flame temperatures during the quench. Because the reactions which produce NO have long timescales, ensuring the quench is "fast" reduces production. The design of the secondary port flows is therefore central to RQL engine emissions performance.

Configuring a combustor in this way results in the majority of air delivered to the reaction passing through the combustor walls in the form of port jets. For modern designs, less than $30 \%$ of the air delivered through the pre-diffuser will pass through the fuel injector (Walker et al. 2008). Because the reaction processes within the combustor are heavily influenced by aerodynamics, the jet flows formed by the ports have significant influence over an RQL system. They control mixing, stoichiometry, residence times and the temperature/velocity profile at turbine inlet.

Experimental studies of combustion system flows commonly adopt sector facilities, where a model combustor is constructed using a segment of the overall annular system (Heitor and Whitelaw 1986; Gnirß and Tropea 2008; Meier et al. 2010; Vishwanath et al. 2018). Sector facilities provide significant advantage for supporting engine development compared with annular test facilities as they require a small percentage of the resources for operation and offer improved accessibility for understanding combustion physics.

Herbon et al. (2017) have reviewed the testing performed throughout an engine technology development program. This succinctly summarises the processes involved in modern engine development, with technology refinement leading to higher complexity validation tests. These tests become increasingly representative of the engine environment as the technology is matured. This work demonstrates the value of both isothermal and sector testing in identifying candidate designs capable of delivering appropriate emissions performance. The challenges of extrapolating fully annular or engine performance from sector tests are also emphasised.

Poor read across to annular test occurs, in a large part, due to the differences in the boundary conditions presented to the combustion system in the sector and annular environments. A principal issue for sector facilities arises in the replication of an appropriate diffuser system, which is used in the engine to expand the air from the compressor into the combustion system. It is well known that aggressive diffusion risks boundary layer separation, resulting from adverse pressure gradient formed at the diffuser wall (Mehta and Bradshaw 1979). For a sector facility, this leads to the rapid growth of confluent boundary layers at the ends of the sector and ultimately stall (Griffiths 1999). The absence of sector boundaries in an annular diffuser permits aggressive diffuser designs, which are used within the engine environment (Fishenden and Stevens 1977).

Walker et al. (2008) and Ford et al. (2012) have shown significant two-way interactions between the combustion system and upstream diffuser feed. Dhopade et al. (2017) additionally found that changes to the diffuser design influenced the mixing performance at combustor exit for an RQL system. This was determined to be a result of changes to the velocity distribution within the annulus. Small variations in the approach velocity to the primary and secondary port jets were shown to significantly affect the mixing within the combustor. These interactions between the diffuser and the combustion system have potential significance for engine design and performance. As the measurements performed in this work enable improved understanding of installation effects, they are of interest to the gas turbine combustion community.

The measurements have, however, been performed under conditions where no fuel is supplied to or burned within the combustion chamber. The results are therefore only of direct relevance to engine operation where the flow dynamics are dominated by isothermal processes. An example of a thermally dominated region of the combustor is the fuel injector flow. Here, heat release results in a local acceleration of the flow (Weber and Dugué 1992). This acceleration occurs predominantly in the bulk flow direction (axial for an annular combustor) and is associated with locally increased turbulence kinetic energy (Heitor and Whitelaw 1986). The acceleration is a direct result of constant pressure combustion, whereby the increase in temperature results in a decrease in density. As mass must be conserved, decreasing the density at constant pressure causes an increase in velocity. In this work therefore, the discussions relating to the fuel injector flow field have been restricted to measurement uncertainty.

The behaviour of port jets has been studied extensively, with reviews provided for both cylindrical and rectangular ducts (Holdeman et al. 1997, 1999). Irrespective of the shape of the combustor liner and port shape, the jet trajectory and the subsequent mixing resulting from the impingement process were found to be primarily affected by the ratio of jet and mainstream momentum, $J$. Holdemann and Chang (2008) subsequently found, perhaps surprisingly, that for constant momentum ratio, the distribution of species (excluding $\mathrm{NO}_{x}$ ) and so the mixing to be largely unaffected by changing the combustor inlet temperature.

The invariance found with preheat does not, however, imply invariance between isothermal and reacting conditions. This is because the accelerations due to heat release 
within the primary zone will decrease the jet momentum ratio. In turn, this means that the reacting flow jets are more prone to deflection downstream, towards the combustor nozzle. The representativeness of the isothermal port jet flows to the engine environment has therefore been investigated and is presented following the description of the fully annular test facility.

\section{Experimental methods}

\subsection{Fully annular combustion system test facility}

Figure 2 shows a schematic of the fully annular test facility into which the scanned PIV system was integrated. A high capacity fan passes filtered air into a $150 \mathrm{~m}^{3}$ plenum located beneath the floor of the test stand. This is then delivered to the vertically mounted test section through a bell-mouthed inlet and honeycomb flow straightener. The test facility is able to operate a 1.5 stage axial flow compressor to deliver pre-diffuser flow structures that are representative of the engine environment (Cha et al. 2012). For these tests, however, the compressor rotor was replaced with a pre-swirl vane row, designed to replicate the approach flow angle provided to the outlet guide vane row by the rotor. This is the configuration shown in Fig. 2 . Air may then be delivered to the test rig at a fixed inlet Mach number by trimming the inlet fan set point.
For the reported measurements, the test facility was operated with a fully featured RQL combustor. This was fitted, complete with cowl, heat shield, fuel injectors and cooling tiles, with design representative of a modern aerospace gas turbine design. The tested combustion system supports 18 equispaced fuel injectors, resulting in a $20^{\circ}$ fuel injector sector. Each sector also contains two pairs of opposed primary ports, which supply air to the reaction zone, and two pairs of opposed secondary ports. For each sector of the combustor tested, one primary port pair was positioned in line with the fuel injector (on a diametral line) and one primary port pair was positioned out of line (on a sector boundary). The secondary ports were also equispaced, with pairs located midway between the primary ports. The mechanical design of the combustion system tested gives rise to a two-sector flow periodicity at combustor exit, as described by Cha et al. (2012).

The instrumentation and control of the facility has been described in detail by Denman (2002) and the aerodynamic design by Wray et al. (1993). The inlet Mach number for the tests performed was set to 0.2 , with an associated Reynolds number of $1.68 \times 10^{5}$ based upon outlet guide vane chord at mid-annulus height. This setpoint was chosen to be sufficiently high to avoid boundary layer transitional affects. Multi-hole pneumatic measurements performed at the prediffuser exit permit definition of the combustion system total pressure loss $\Delta P_{O}$. The ratio of this with the total pressure measured at pre-diffuser exit $P_{O_{30}}$, for the system measured is

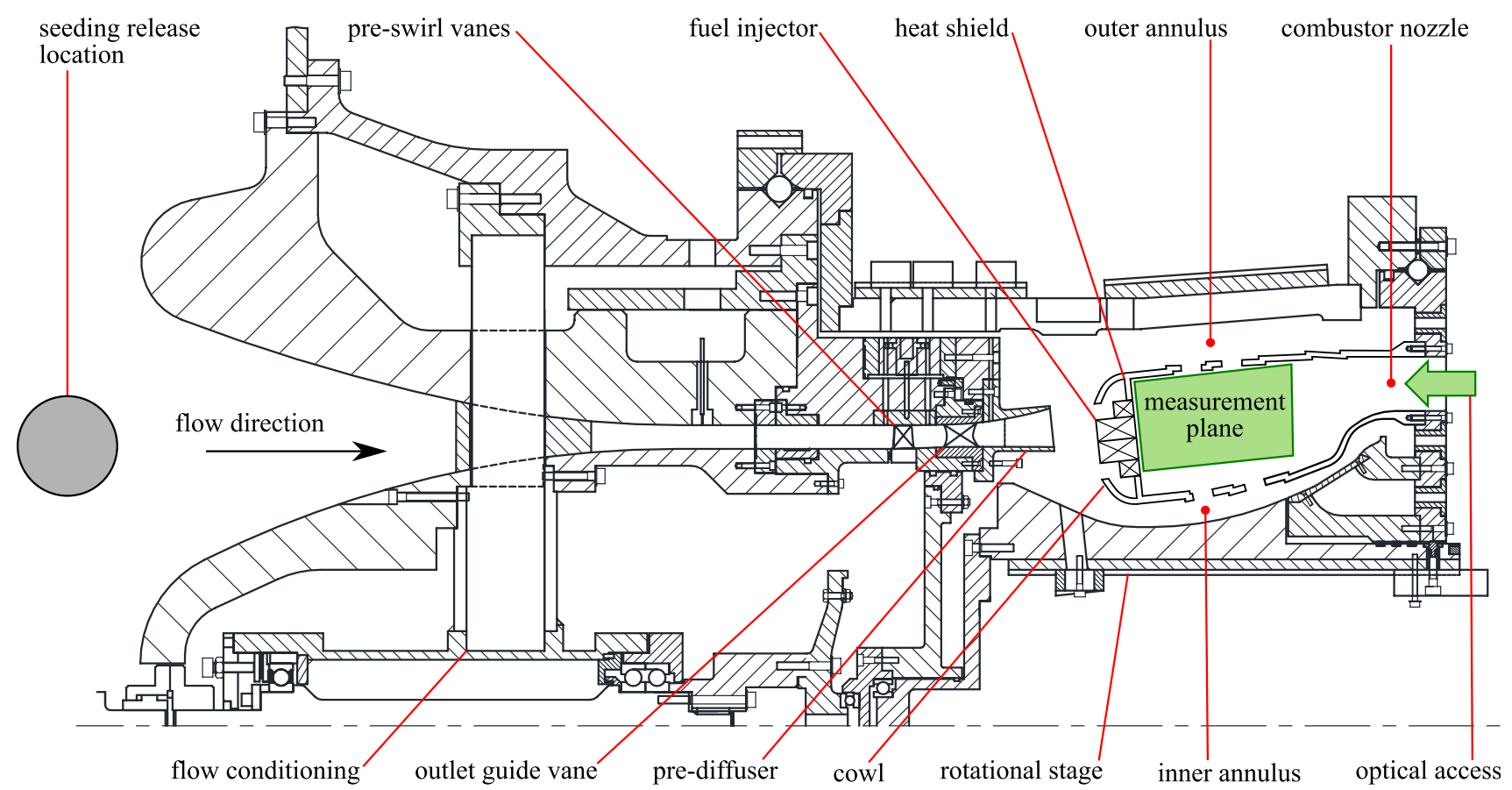

Fig. 2 A schematic detailing the annular test facility on which the measurements were performed 
equivalent to $85 \%$ of the design point, when scaled to engine operating conditions.

In order to assess the relevance of the isothermal facility to engine operating conditions, momentum ratios have been calculated (1), following Holdemann and Chang (2008). Here the density is given by $\rho$ and the bulk velocity by $U$; the subscripts $j$ and $m$ refer to the port jet and main combustor flow, respectively. To evaluate this for an engine condition, the combustion is modelled to first order as a uniform, adiabatic temperature increase in the gas supplied to the primary combustion zone. A conservative temperature rise has been assumed; the entire primary zone mixture raised to the upper adiabatic flame temperature, $2500 \mathrm{~K}$ for JET-A1. As discussed, this will not happen in an RQL combustor, with temperatures maintained at lower levels by oxygen depletion. By assuming constant mass flow rate through the combustor at constant pressure, the relative bulk acceleration of the gas may be estimated.

$J=\frac{\rho_{j} U_{j}^{2}}{\rho_{m} U_{m}^{2}}$

For the primary ports, at the high power engine condition from which the annular facility is scaled, $J_{\text {eng }}=33.9$ and for the isothermal condition, $J_{\text {iso }}=94.5$, almost triple the engine value. Increased momentum ratio suggests a reduced tendency for the jet flow to be deflected downstream. The values calculated for both the engine and isothermal experiment are both high, however, indicating that the port jet momentum flux is significantly higher than that of the combustor flow and so deflection is unlikely.

Where momentum ratios are known, the jet penetration regime may be assessed based upon the port spacing $S$ and combustor radial height $H$. An empirically defined constant (2) approximately defines the level of penetration. For the combustor configuration tested, values of $C \gtrsim 2.5$ indicate gross overpenetration, where substantially more momentum is supplied to the port jets than is required for the port jets to impinge (Holdeman 1993). $C$ was therefore estimated for the engine and isothermal conditions, $C_{\mathrm{eng}}=3.1$ and $C_{\mathrm{iso}}=5.2$, respectively.

$C=\left(\frac{S}{H}\right) \sqrt{J}$

The values calculated indicate that for both the engine environment and the isothermal experiment, the port jets will remain within the gross overpenetration regime, with some margin. The implication of this is that the jet trajectory will remain relatively insensitive to changes to the combustor flow. The port jet momentum flux is sufficient to overcome any deflection imposed by the flow through the combustor even after acceleration due to combustion.

Details of the mixing process may not be well replicated by the isothermal experiment. As the isothermal jet momentum is higher, the jet collision and impingement converts more mean kinetic energy to turbulence and so performs more mixing work. Mixing, however, is not measured in this study. The measurements consider instead the bulk mass transport processes, which, because of the dominance of the port jets, are expected to be a reasonable first-order representation of those within the engine.

\subsection{Scanned volumetric PIV measurements}

The PIV system was integrated into the annular facility, with a custom support structure built off the central rotational stage. This stage, shown in Fig. 2, replicates the geometry of the inner pressure casing and is designed for traversing multi-hole pneumatic sensors within the inner annulus duct. It is mechanically driven by a geared stepper motor mounted to the upper surface of the test facility.

A photograph of the support and measurement system installed on the annular combustion system test facility is shown in Fig. 3. Two cameras view the laser light sheet in the back-scatter-back-scatter configuration. The mechanical arrangement results in the measurement of radial-axial planes. By moving the rotation stage, the entire PIV system was rigidly traversed circumferentially, with volumetric statistics of the combustor flow assembled from measurements performed at multiple traverse locations. Figure 3 shows the system in a raised position, so that the instrumentation may be clearly seen. For the measurements performed, the

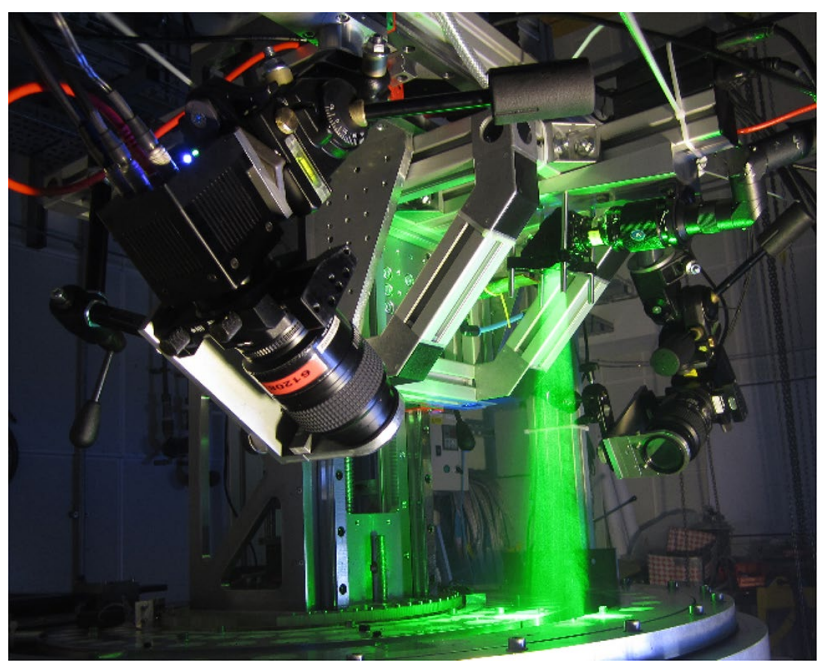

Fig. 3 A photograph showing the PIV system installed on the annular test facility. The photograph shows the PIV support structure in raised position ready for camera calibration, with the laser sheet projected towards the combustor nozzle 
cameras were positioned closer to the test facility, typically a few millimetres above the nozzle exit plane.

Because of the restricted optical access to an unmodified aerospace combustor, measurements were only achievable through the combustor nozzle, looking upstream. This configuration presented several challenges which had to be overcome in order to successfully deliver the measurements:

- The cameras directly viewed the laser light sheet at the point it was projected onto the test geometry, resulting in high levels of flare and blooming.

- When on test the camera lenses and laser delivery optics were positioned in the air stream, a few millimetres from the nozzle exhaust. If unmanaged, seeding accumulation prevented clear laser projection/imaging.

- Due to the high accelerations through the combustion system, the seeding distribution was clipped. The seeding delivered to the combustor consisted of only the smallest generated seeding particles.

- To obtain an appropriate view of the laser light sheet through the nozzle, precise camera positioning was required.

- The mechanical design of the combustion system prohibited positioning of a camera calibration target precisely within the combustor.

Seeding was delivered upstream of the test rig flow conditioning, using a PIVTec PIVPart 45 seeder to atomise diethyl hexyl sebacate. The expected seeding diameter is defined by the manufacturer as less than $1 \mu \mathrm{m}$, consistent with the median drop size reported by Ragni et al. (2011). The approximate location of seeding delivery is marked in Fig. 2, with the seed released upstream of the test facility within the inlet plenum. Seed was provided by means of a rake fitted with an impingement plate. In order that seeding density be optimised, the seeding delivery rake was affixed to a radial-circumferential traverse.

Stagnation pressure measurements were taken at prediffuser exit to assess whether seed delivery influenced the upstream flow. A $1 \mathrm{~mm}$ pitot static probe was traversed across the pre-diffuser exit plane, with the measurement spanning the full diffuser height over a $20^{\circ}$ sector. This traverse was performed with the seeder position fixed, both with and without seed delivery. No difference between the seeded and unseeded measurements was found.

The laser delivery optics were mounted directly to the PIV support structure. Laser energy was delivered from a Litron Nano-T-PIV 135-15 using a LaVision laser guiding arm. Attenuation of the laser beam was achieved using a motorised half wave plate prior to the second harmonic generator within the laser head. Adjustable beam waisting was provided using a LaVision supplied Galilean telescope and beam expansion with a cylindrical lens $(-20 \mathrm{~mm}$ focal length). The laser delivery optics were mechanically fixed to the support structure using a wedged plate. The wedge angle was matched to that of the light sheet so that the laser sheet approached the outer wall of the combustor obliquely. By delivering the laser light in this way, flare from the outer wall was minimised.

Two Imperx Bobcat B2020 cameras fitted with Scheimpflug adapters and Carl Zeiss Planar 1.4/50 lenses were used for imaging. The cameras were positioned so that the projection of the laser sheet onto the fuel injector and heat shield was imaged, enabling measurements of the combustor near field. As the heat shield and fuel injector effectively form a laser beam stop, substantial scatter was imaged, resulting in saturation and charge bleed through the CCD vertical shift registers or blooming.

The entrance pupil of each camera lens was therefore fitted with both polarising and bandpass filters. The polarising filter was rotated to provide maximum attenuation of the laser energy scattered from the combustor heat shield, largely eliminating blooming. Polarisation control of background scatter is not commonly used for PIV measurement, as light scattered from the seeding is not highly polarised. Configuring polarisers to transmit laser illumination therefore results in limited improvements to image contrast. For the annular measurements performed here, however, the scattered return from the heat shield and fuel injector was observed to preserve the polarisation state of the laser. Polarised filtering therefore resulted in significant improvements to image contrast. In particular, the non-diffuse scatter, from angled metal surfaces forming the combustor inlet geometry was attenuated. These reflections are particularly problematic for PIV measurement, as they result in saturation, blooming and contamination of large areas even at low laser energy.

With the polarising filters fitted, the images of the seeding particles were attenuated significantly. Higher laser energies were therefore required in order to record images of the seeding particles. For the bandpass filtered case, a laser pulse energy of $1.5 \mathrm{~mJ}$ was sufficient; however, where polarisation was additionally filtered, energies of $39 \mathrm{~mJ}$ per pulse were required for equivalent illumination. Because the laser remained stationary within the laboratory and the laser light was delivered to the rotating support structure by a sequence of mirrors built into the guiding arm, the laser polarisation state was rotated by the angular motion of the central rotation stage. At the time of the testing, an appropriate half wave plate was not available to compensate for this and so the polarising filters fitted to the cameras were rotated to achieve large scan areas. In order to minimise the effects of seeding contamination, the imaging filters and laser delivery optics were enclosed in a custom sealed filter mount, flush fitted with an oleophobic window. 
Because of the geometry of the combustor, it was not possible to deliver and image laser light across the full radial height of the combustor. The contraction of the combustor nozzle was such that both delivered laser light and the camera view were interrupted. For the RQL combustor tested, the maximum field of view was achieved by biasing the measurement towards the outer wall. This means that no data are measured at the inner combustor wall.

Calibration of the stereoscope was performed using a LaVision type 106-10 multi-layer calibration plate. As the target could not reasonably be positioned within the light sheet inside the combustor, the PIV support was manufactured with a motorised axial traverse stage. This enabled rigid translation of the cameras and laser delivery optics vertically, such that the camera views moved outside the combustor, as shown in Fig. 3. Raising the cameras in this way allowed the calibration plate to be precisely placed within the laser light sheet, outside of the annular test facility. Calibration images were then recorded and the traverse returned to the measurement position, with the camera lenses located approximately $5 \mathrm{~mm}$ from the combustor nozzle exit plane. Fine tuning of the calibration was subsequently performed using auto-calibration, achieving disparities of 1px or less.

Prior to PIV analysis, the recorded images were preprocessed using an 11-image sliding average subtraction. A custom image mask was defined for each measurement plane to eliminate regions of the image in which seeding was not observable. Vector calculation was performed using adaptive window deformation with $24 \times 24 \mathrm{px}$ final window size at $75 \%$ overlap. Vector post-processing was then performed

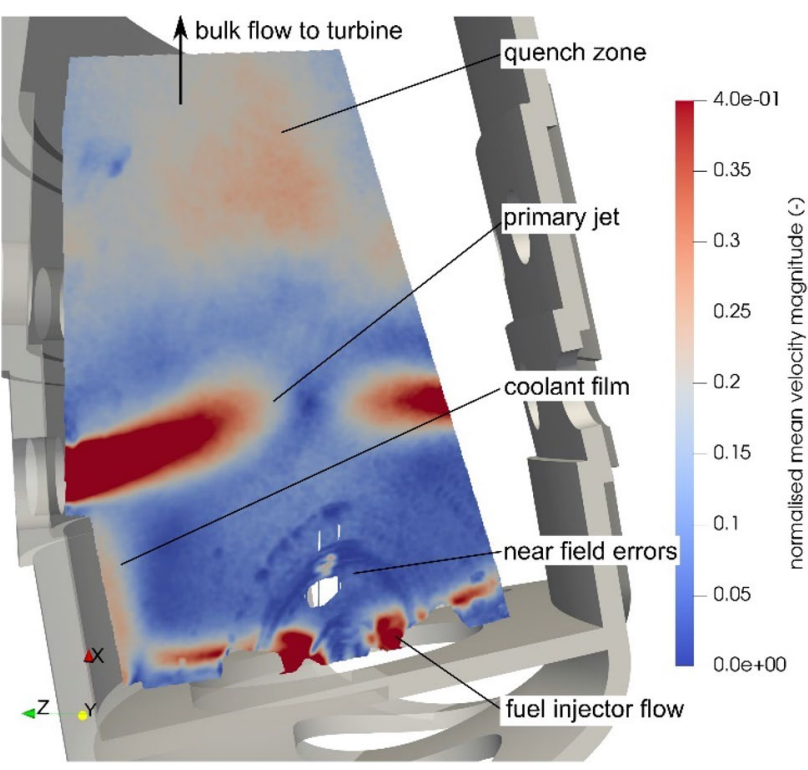

Fig. 4 A sample measurement, recovered on the fuel injector centreline. This shows various features measured on the fuel injector centreline measurement plane using universal outlier detection and single-point statistics calculated without interpolation or smoothing. A velocity scale $U$ has been derived from total pressure loss across the combustion system: $U=\sqrt{2 \Delta P_{o} / \rho}$ and used to normalise the velocities presented.

An example of the measured average velocity magnitude is shown at the fuel injector centreline location in Fig. 4. For reference, a solid model that is representative of the combustor has been rendered alongside the velocity field. Several features are clearly observed in the measured field and have been annotated. Because the combustor nozzle blocks the view of the cameras, the measurement does not extend across the full radial height of the combustor. Elevated velocity magnitude is observed at localised regions within the flow field. In the quench zone, this occurs due to the addition of significant momentum to the combustor through the secondary ports.

The secondary port jets are not observed in Fig. 4, as for the combustor measured, these are positioned between the primary ports. Because the plane shown was measured on the fuel injector centreline, the primary port jets are instead clearly measured issuing from the combustor wall. The measurement indicates the inner and outer primary port jets propagate towards one another, resulting in jet impingement.

Elevated velocity is also observed close to the combustor liner in bay 1. This corresponds to the film cooling system used to protect the liner from the temperatures generated within the combustor. As gas temperatures routinely exceed the operating limit of the combustor walls, cooling is required to meet lifing requirements.

The fuel injector flow is also measured, propagating radially across the heat shield, albeit with some structural errors. These present as low-velocity intrusions to the high-velocity magnitude flows extending from the injector towards the combustor walls and appear in the measured field as unphysical discontinuities the fuel injector jet. This is a measurement artefact, occurring because geometry on the heat shield is imaged through the laser light sheet. These effects are pronounced in the primary zone due to the proximity of the fuel injector and heat shield to the laser beam, an undesirable consequence of performing the measurement through the combustor nozzle.

In order to reconstruct volumetric data, the PIV support structure and seeding delivery rake were incrementally traversed by $1^{\circ}$ between measurement locations. At each measurement location, 200 stereo image quads were recorded and the oleophobic windows cleaned. As the combustor tested has two-sector geometric periodicity, the total measurement scanned $40^{\circ}$. Rotation of the polarising filters was performed between the measurements of the left- and right-hand sectors and a separate camera calibration therefore performed for each measured sector. 


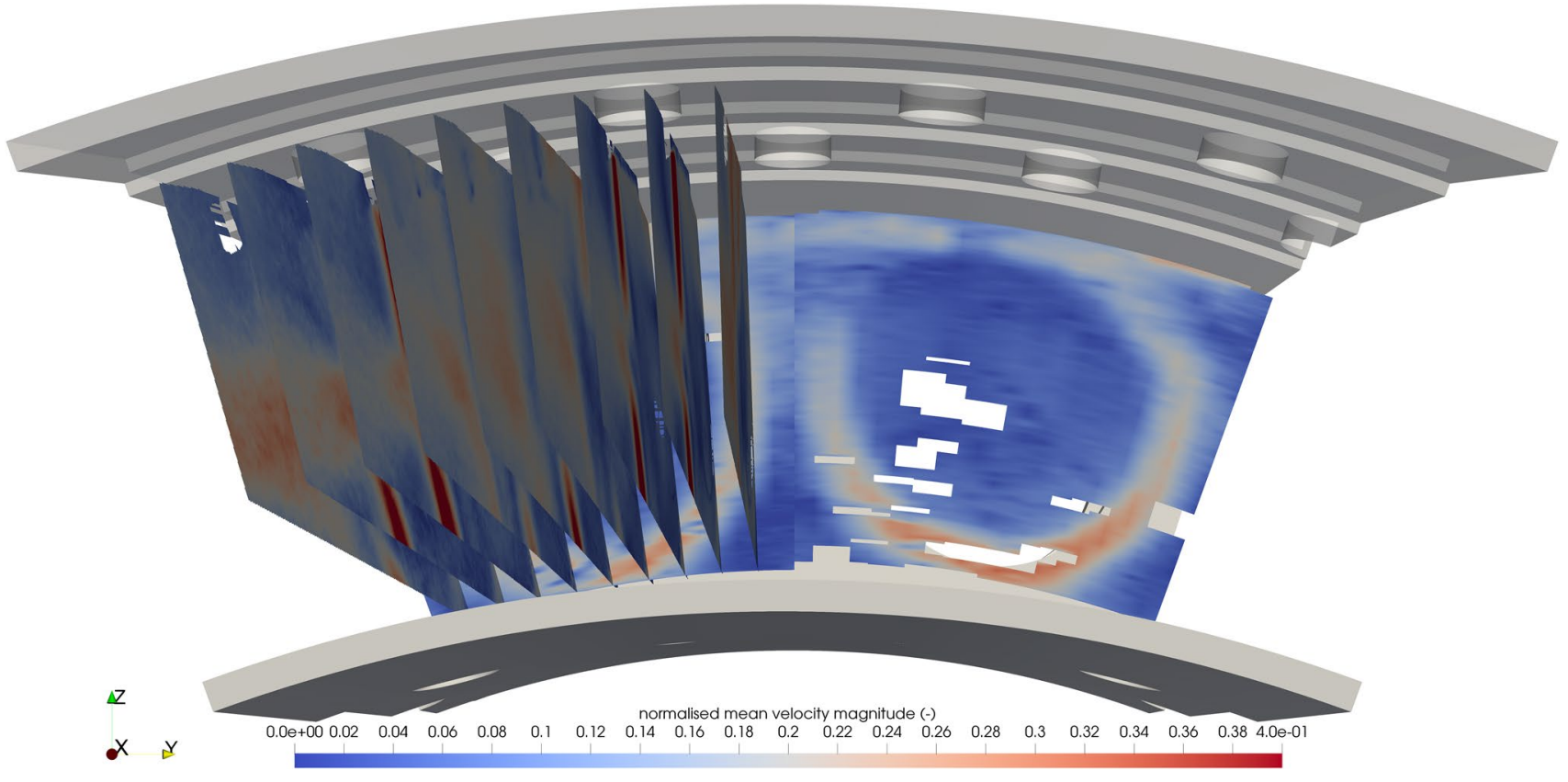

Fig. 5 A render illustrating the reconstruction of volumetric data from measurement planes

The reconstruction of measured planes into volume data from which any associated plane may be interpolated is illustrated in Fig. 5. A subset of the recorded planes across the circumference of the combustor is shown along with an interpolated orthogonal plane. As the PIV data were masked to minimise contamination of the velocity fields from flare, some invalid data are present within the measured velocity volumes. This is shown as transparent regions within the rendered data and has been neglected from the analysis performed.

\subsection{Uncertainty}

PIV measurement uncertainty is challenging to assess, as the contributing sources are varied, associated with the specific installation and the flow measured. Detailed reviews of these sources and the methods used to quantify them have been prepared (Wieneke 2017; Sciacchitano 2019). Stereoscopic PIV measurements combine the uncertainty from individual displacement measurements of each of the cameras but also the camera calibration function. Bhattacharya et al. (2016) developed a framework to quantify this, with typical uncertainties reported in the range 0.07-0.4 pixels (Sciacchitano 2019). The measurement plane normal velocity uncertainty was found to be 2-3 times larger than the inplane. Assuming that camera registration may be accounted for to leading order by auto-calibration, the uncertainty may be calculated for each $2 \mathrm{C}$ measurement using the correlation statistics method (Wieneke 2015) and propagated to the reconstructed $3 \mathrm{C}$ vector (Wieneke 2017).
These a posteriori assessments are, however, not well suited to the structural sources of uncertainty associated with the experiment described. As discussed with reference to Fig. 4, the relative orientation of the cameras, laser and geometry results in small distances between the light sheet and combustion system where the measurement plane meets the combustor geometry. As the cameras are focused on the light sheet plane, the finite depth of field of the camera lens results in features from both the heat shield and fuel injector being imaged. This occurs despite the imaging lenses being set for shallow depth of field (f\#/1.4). Measurement error from this rapidly decreases with axial position due to the loss of spatial frequency from the background image. Where the combustor is imaged with reasonable clarity, the resulting correlation peaks are biased towards zero, a result of the geometry not moving between exposures. This leads to the low velocity magnitude intrusions identified in the fuel injector jet flow, shown in Fig. 4. These artefacts are particularly problematic close to the heat shield and fuel injector, although some artefacts are also measured close to the combustor outer wall. For example, a small deficit in the near wall flow is observed in Fig. 5, close to the 12 o'clock position for the right-hand sector.

The correlation statistics method returned low uncertainties for these artefacts because the background image resulted in well-formed correlation peaks. For this reason, an uncertainty assessment was additionally performed using the divergence of the mean field. As the flow is incompressible, any residual divergence must be due to some uncertainty, which may be propagated to a velocity (Sciacchitano and 
Wieneke 2016). This propagation requires some knowledge of the covariance of the error, which was assessed using the correlation statistics methods implemented in DaVis 8.4 (Wieneke 2015). The net covariance was calculated from the Frobenius norm of the covariances and found to be 0.5027 .

The slip velocity of the particles was also assessed from the instantaneous measurement data. The in-plane particle acceleration vector was calculated from the spatial gradient of the velocity field. The seeding particle diameter $d_{\mathrm{p}}=1 \mu \mathrm{m}$ was defined from manufacturer supplied data, seeding density $\rho_{\mathrm{p}}=910 \mathrm{~kg} / \mathrm{m}^{3}$ and air viscosity $\mu_{\mathrm{f}}=18 \mu \mathrm{Pa}$ s. The assumption of Stokes flow implicit to the derivation of the slip velocity (Grant 1997) applies only for low particle Reynolds number. For the measurement data $R e_{\mathrm{p}} \leq 0.11$ was found, well within the Stokes regime.

Slip velocities and the correlation statistics uncertainty method were evaluated using instantaneous data and propagated to the average by standard error. The divergence uncertainty was calculated from time averaged data, as each plane was measured at a different point in time. The distribution of each uncertainty assessment was then calculated, and these are compared in Fig. 6.

The results show the uncertainty due to slip to be negligible and the divergence method to provide the largest uncertainties. This is to be anticipated, as residual divergence will include uncertainty sources not captured by the correlation statistics method. Examples of these include uncertainty in the positioning the scanned system, variations in test facility condition between scan planes and uncertainty in the camera calibration. Some uncertainty of this form is apparent from the small mismatch observed between the two-sector measurements shown in Fig. 5.

Calculating the standard deviation of the normalised velocity uncertainty from the divergence method, corrected by the appropriate Student's t-distribution factor, a normalised velocity uncertainty of \pm 0.027 is found for a $95 \%$ confidence interval. Evaluation of the displacement uncertainty

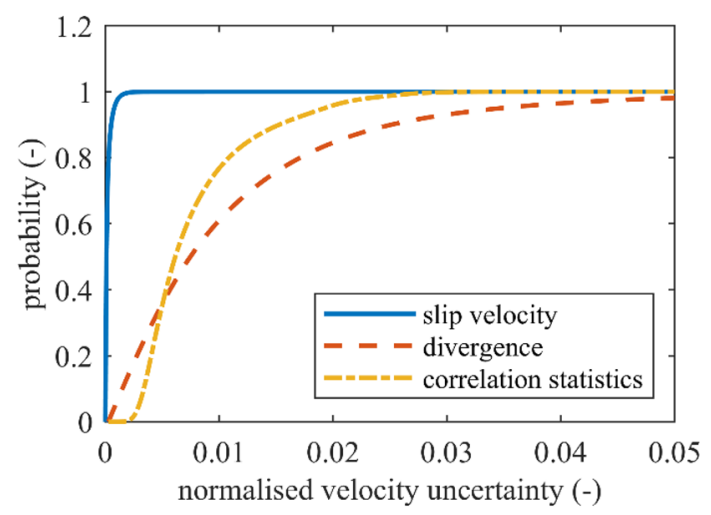

Fig. 6 Cumulative distribution functions for normalised velocity uncertainty determined using the correlation statistics method, again multiplied by the relevant Student's t-distribution factor gave a correlation uncertainty of $\pm 0.73 p x$, which is somewhat higher than that reported by (Sciacchitano 2019). Inspection of the spatial distribution of uncertainty using both the divergence and correlation statistics methods leads to the conclusion that the highest uncertainties are associated with regions close to the combustor outer wall and near to the heat shield. This is a direct consequence of reduced contrast due to the high levels of background scatter.

\section{Results and discussion}

In order to improve understanding of the three-dimensional flows within a gas turbine combustor, streamline tracers have been used to mark the average port jet flows. These are shown for the primary jets in Fig. 7. Three views of the combustor have been rendered to describe the 3D trajectory of the port jet flows. Figure 7 a provides an axial view looking upstream (from the combustor nozzle towards the fuel injector) and shows the radial, tangential mass transport. A radial view is shown in Fig. 7b, directed outboard and similarly shows the tangential, axial flow. Figure $7 \mathrm{c}$ provides an isometric view to illustrate the 3D trajectory of the port jets.

For the flows shown in Fig. 7, differences are observed between the jets located in line with the fuel injector, and those that are out of line, located at the sector boundary. Figure 7a shows that all of the outer port jets flow towards their equivalent inner port jet close to the centre of the combustor. In Fig. 7b, c, however, it is observed that the inline port jets propagate directly towards the centre of the combustor, where they impinge. Air delivered through the primary ports is both recirculated towards the fuel injector, into the primary combustion zone, and also transported downstream towards the combustor nozzle. The out-ofline jets do not impinge, but instead propagate directly downstream. Figure $7 \mathrm{c}$ shows some subtle differences in the behaviour of the port jets for the two sectors measured. The out-of-line port jet at the left-right sector boundary approaches at a shallower flow angle than at the periodic sector boundary.

The reason for the difference in trajectory between the inline and out-of-line jets has been investigated. As the geometry of the primary ports is constant, the difference in trajectory must be a result of the port jet boundary conditions. It is possible that the out-of-line port enters the combustor with a different proportion of axial and radial momentum compared to the inline port. This variation could reasonably arise due to circumferential variations in the upstream annulus flow. In this case, the out-of-line port jet would already possess higher axial momentum 


\section{$\equiv$ inner primary port jet \\ $\bar{\equiv}$ outer primary port jet}

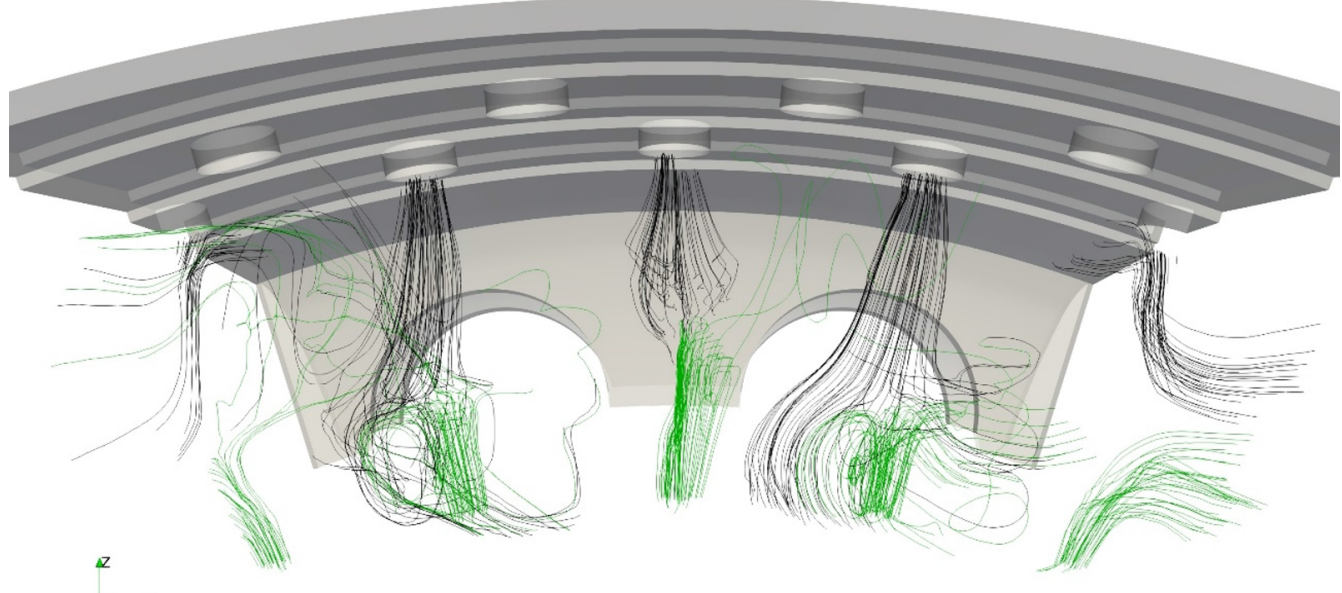

(a) axial view, looking upstream

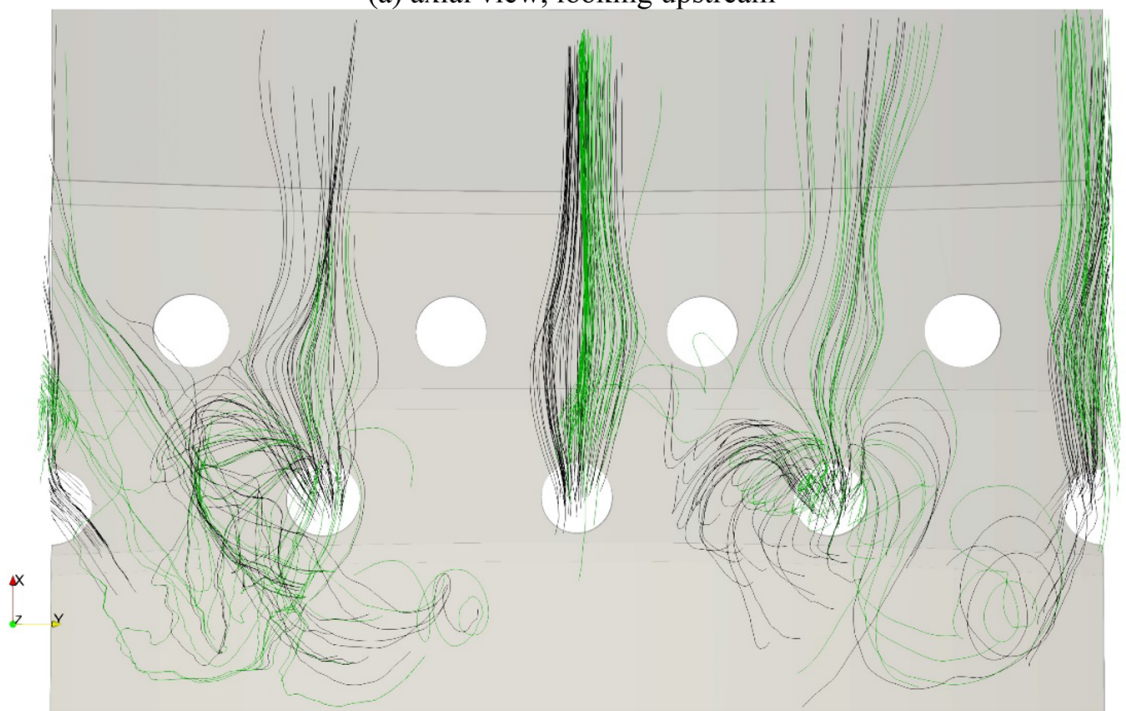

(b) radial view, looking outboard

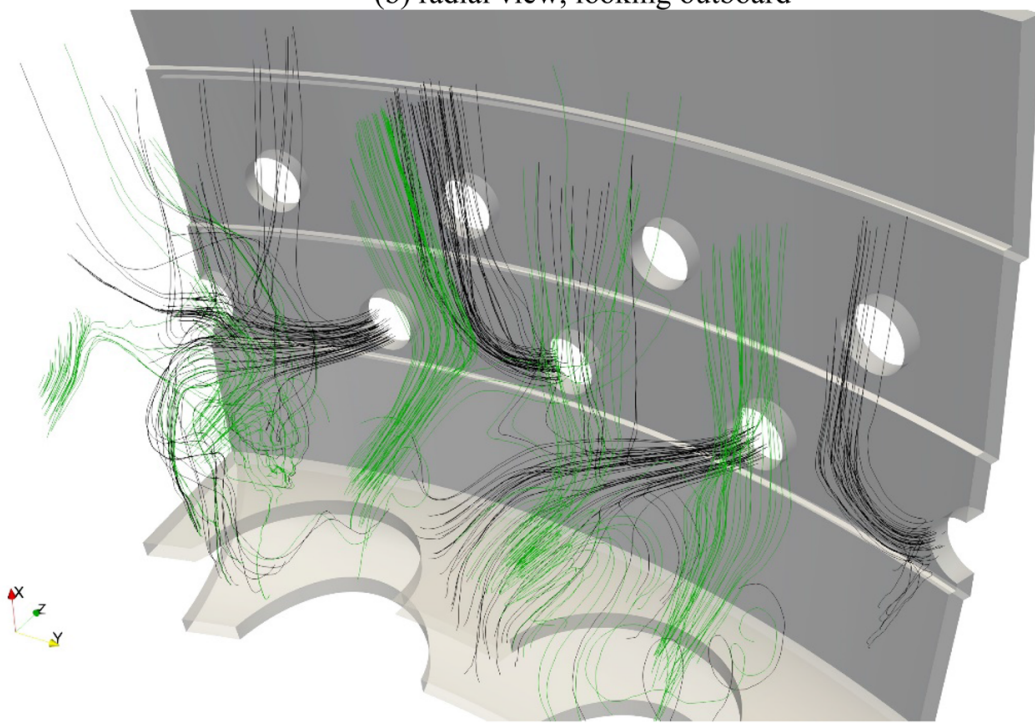

(c) isometric view

Fig. 7 Streamlines illustrating primary port jet interaction and mass transport mechanisms 


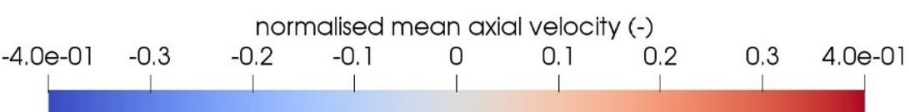

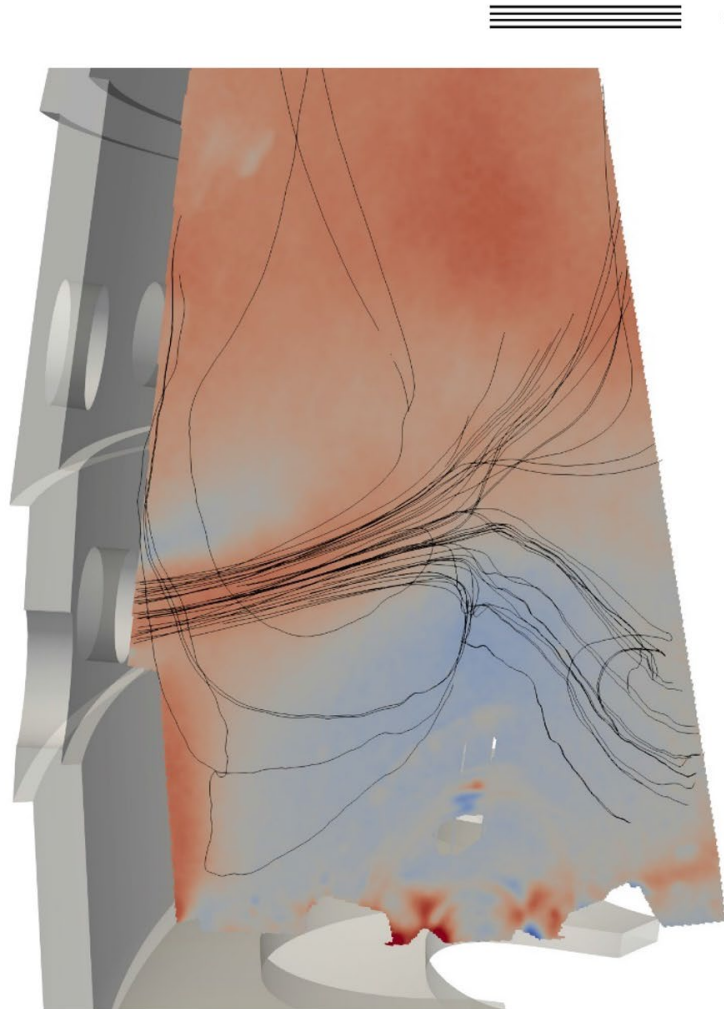

(a) measurement plane inline with fuel injector outer primary port jet

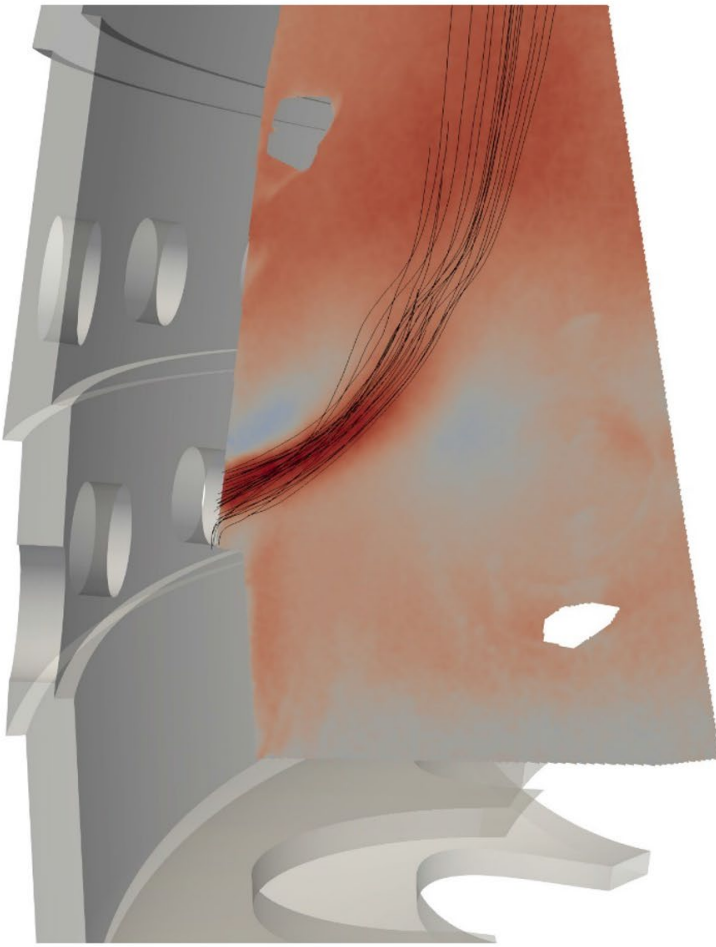

(b) measurement plane out of line with fuel injector

Fig. 8 Axial velocity showing the outer primary port jets, 3D streamline tracers mark the port jet trajectory

upon entering the combustor and therefore its initial trajectory would be directed downstream. Alternatively, the out-of-line port jet could have a lower momentum ratio than the inline, resulting from either a weaker port jet or an increased combustor flow. This change in momentum ratio would equally result in deflection of the out-of-line port jet.

Figure 8 shows contours of axial velocity on radial-axial planes located through the centres of the inline and out-ofline ports. The average port jet trajectory has been highlighted using of streamline tracers. The plots show that the axial velocity profile of the port jet is approximately constant as the jet crosses the combustor mainstream. The axial velocity contained within the out-of-line primary jet is shown to be approximately double that of the inline jet flow across much of the length of the jet. Because the axial component of velocity within the port jets is constant as it initially propagates through the combustor, any change in trajectory from in-combustor deflection must occur close to the point of entry into the combustor. The axial velocities of the bay 1 film cooling system, upstream of the outer primary, jet are well resolved by the PIV measurement. These show the axial velocities on the inline plane (Fig. 8a) to be higher than the out-of-line plane (Fig. 8b), suggesting that a momentum ratio-induced deflection of the jet should be greater for the inline plane. This is not the case, however, the port jet must have entered the outof-line location combustor with greater axial momentum, due to variations in the velocity field within the annulus.

Multi-hole pneumatic measurements were taken within the annulus, upstream of the primary port during commissioning. The data measured agree very well with conclusions reached from the PIV survey. The anulus velocity upstream of the out-of-line port was measured to be approximately double that upstream of the inline port. It is therefore expected that the upstream annulus velocity distribution causes the difference in behaviour between the inline and out-of-line ports.

The curvature of the out-of-line jet occurs as a result of the relative magnitude of axial and radial velocity components. As the port jet travels across the combustor, the magnitude of the radial velocity decreases (presumably due 
to the pressure field generated by the interaction with the opposing jet), whereas the axial component remains constant. The persistence of the axial component is expected, as the combustor was designed for constant pressure combustion with axial exhaust to the turbine. Because the out-ofline port is identified as being deflected downstream, it is expected that this effect would also occur within the engine where the propensity for jet penetration is decreased due to reduced momentum ratio.

As the out-of-line port is more likely to be deflected downstream under engine operating conditions, it could be assumed the same reasoning may be applied to the inline port jet. Deflection of the port jet at this location is unlikely however, due to non-uniformity in the combustor flow due to the action of the fuel injector. This generates a central recirculation within the primary zone, which results in fluid being returned towards the fuel injector at combustor midheight at the inline port location. This is shown by negative axial velocities which are located between the port jet and fuel injector in Fig. 8a. This recirculation must remain under reacting conditions as it is central to the function of the combustor. Returning combusting mixture towards the fuel injector in this way is the mechanism by which combustion is maintained and the flame stabilised. Because the flow must be locally directed towards the fuel injector across the majority of the inline jet's trajectory, aerodynamic forcing from the main stream cannot deflect the jet downstream at engine conditions. The primary port trajectories measured are therefore expected to provide first-order approximation of that which would occur under engine operation.

A similar evaluation may be made of the secondary port jets. Streamline tracers illustrating the mass transport associated with these are shown in Fig. 9, with equivalent views to Fig. 7 provided. Figure 9a shows the radial penetration of the secondary port jets and indicates that, unlike the primary port jets, each of the inner secondary jets directly impinges on the corresponding outer jet. This impingement occurs close to the mid radial height of the combustor. Figure 9c shows the streamlines travelling radially towards combustor mid-height where the impingement process results in a sudden $90^{\circ}$ deflection to the axial direction, before flowing downstream towards the combustor nozzle.

For an RQL system, the secondary port jets are used to supply fresh air to the reacting mixture, in order to rapidly decrease the equivalence ratio. This minimises the time at which stoichiometric mixtures exist and reduces the maximum gas temperature, decreasing thermal NO production. To ensure uniform dilution across the combustor, high levels of mixing are desirable. Secondary port flows therefore aim to generate turbulence across a wide range of length scales, promoting the rapid distribution of coolant and so providing uniform quenching. The rapid change in direction of the port jet shown by the time averaged streamlines suggests good performance, as it indicates significant momentum transfer.

The level of turbulence generation has been quantified by the turbulence kinetic energy (TKE). Three-dimensional contours of the upper 15\% of TKE have been rendered in Fig. 10, with streamlines released from both the primary and secondary ports for reference. High levels of TKE are collocated with the secondary port jet impingement as well as at various locations close to the fuel injector. The occurrence of high turbulence levels at the point where the secondary port jets impinge indicates high levels of mixing, which is desirable for the quench process. Increased turbulence promotes mixing and so distribution of the annulus air used to quench the combustion reaction.

Scattered regions of elevated TKE are also measured towards the upstream end of the combustor, close to the heat shield. Much of this high TKE is due to measurement error. This occurs because of the relative viewing angle of the cameras to the light sheet, which results in partially focussed imaging of the combustor through the light sheet. This is pronounced close to the heat shield due to the short distance between the light sheet and combustor, a result of the laser delivery/imaging arrangement. It is noteworthy that the impingement of the secondary port jets results in more significant TKE generation than the fuel injector flows, which rely upon the generation of turbulence at a wide range of scales to efficiently mix fuel for combustion. TKE within the impingement region of the inline primary port jets is approximately $60 \%$ of that measured for the secondary port jets. Likely this occurs due to a reduced momentum ratio for the primary ports and is associated with the upstream annulus velocity distribution. No increased TKE was measured associated with the out-of-line primary port jets, due to the absence of any impingement.

Figure $9 \mathrm{~b}$ demonstrates the circumferential variation in jet trajectory. Each opposed pair of secondary port jets moves away from the sector boundary, towards the fuel injector centre. This is clearly observable in Fig. 9b, as the combustor wall is visible downstream of the inline primary ports due to the absence of any streamline tracers marking port flow. Figure 10 shows that the migration away from the sector boundary, towards the fuel injector centre, is a direct result of the out-of-line primary jets. These pass between the secondary jets on the sector boundaries due to their increased axial momentum.

As with the primary jets, the acceleration occurring in the combustor mainstream due to combustion will result in a greater propensity for the secondary jets to be deflected downstream. The increased TKE measured for the secondary jet impingement indicates that secondary port momentum is higher than that of the primary ports. Due to the relatively low combustor velocities and the absence of any significant bulk swirl, this can only arise due to the upstream 


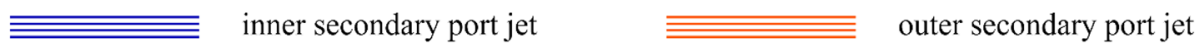

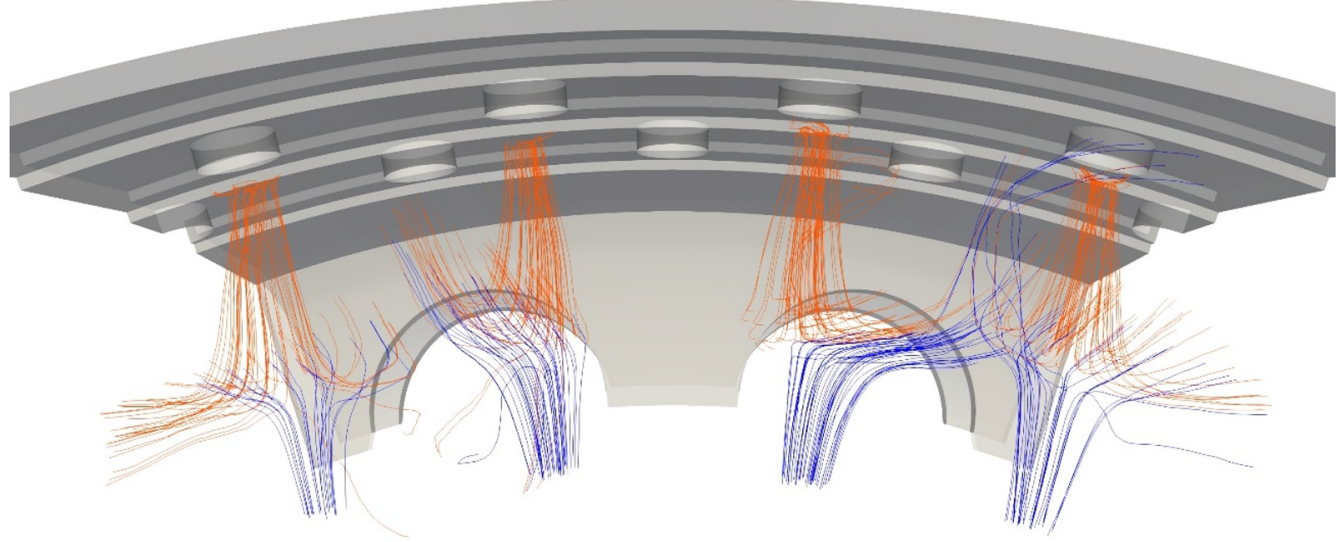

$a$

$x y$

(a) axial view, looking upstream

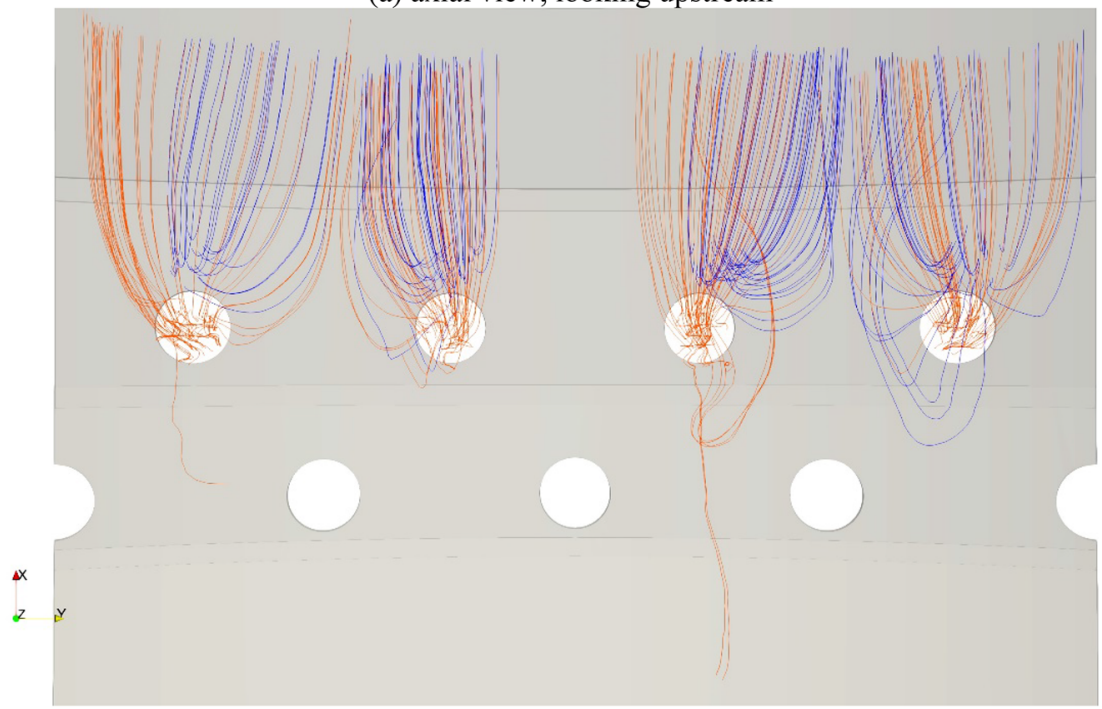

(b) radial view, looking outboard

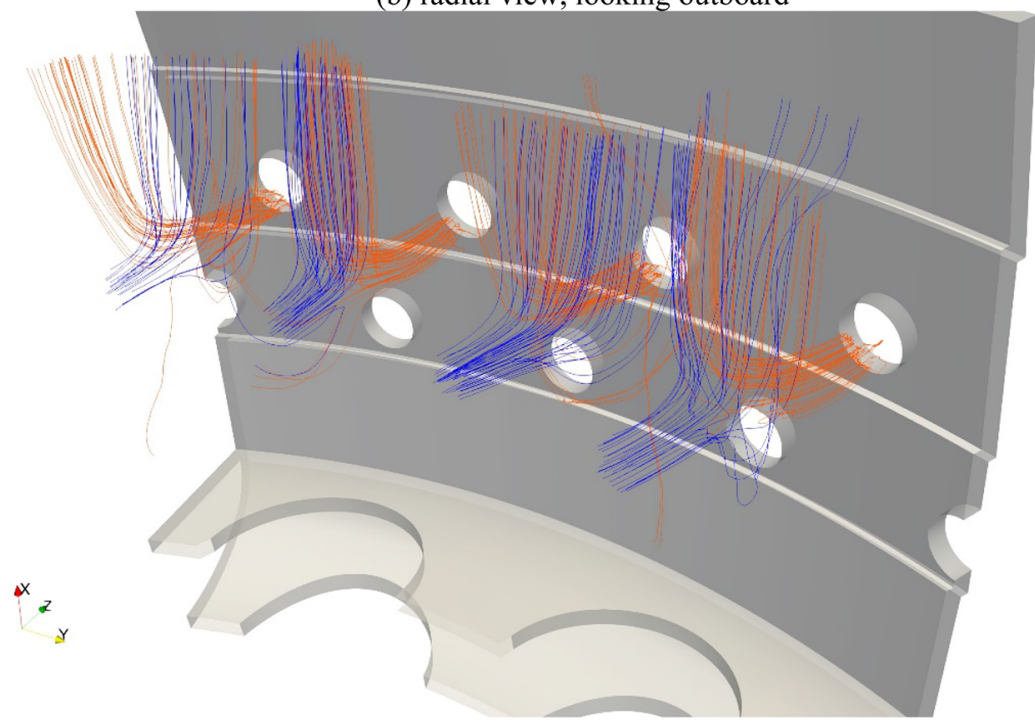

(c) isometric view

Fig. 9 Streamlines illustrating secondary port jet interaction and mass transport mechanisms 


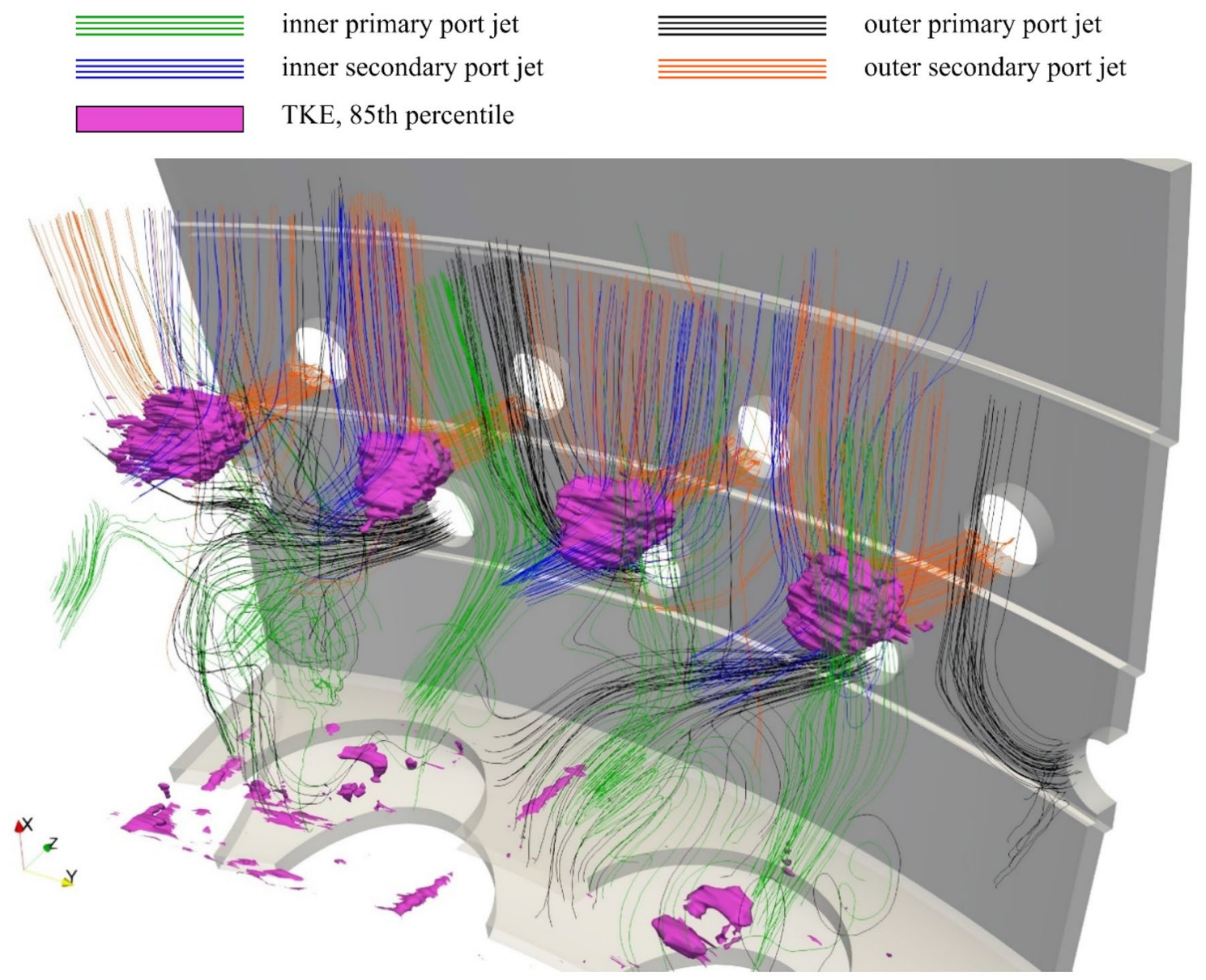

Fig. 10 Streamlines illustrating secondary port jet interaction and mass transport mechanisms, with elevated level TKE contour shown

total pressure distribution within the annulus. As the annulus velocity fields are non-reacting, these will scale well to engine conditions, suggesting that the measured increases in secondary port momentum and TKE generation will occur at engine conditions. The described circumferential migration towards the fuel injector centreline due to the passage of the primary port jets is also expected to occur under engine operating conditions. This is the result of the migration of primary ports downstream, which, as already discussed will be enhanced by combustion.

It is difficult to assess whether the secondary jets will in fact impinge in the engine environment, as is measured in the isothermal experiment. RQL combustors aim to continue the combusting reaction downstream of both the primary and secondary port dilutions. This means that the mixture will continue to release heat and accelerate (albeit at a lean equivalence ratio) throughout the combustor, suggesting a greater propensity for deflection of the secondary ports than the primary ports. However, as already discussed, the central recirculation caused by the fuel injector results in flow reversal. This means that the mass transport from the primary zone downstream will not be uniformly distributed around the combustor. Velocities in regions away from the fuel injector, at the sector boundaries and close to the combustor walls will therefore be higher than would be estimated from bulk flow calculations. This non-uniformity combined with the stoichiometric evolution of the combustion process prohibits reasonable first-order assessments of the secondary port jet momentum ratio. The measured migration of the secondary ports towards the injector centreline as a result of locally increased mainstream momentum due to the primary jets, suggests that the secondary jets may be less susceptible to deflection than the primary jets and so could reasonably impinge under engine operating conditions. This is supported by the analysis of the engine and isothermal bulk port flows, which found both to lie within the gross overpenetration regime.

\section{Conclusions}

This work details the development of a novel PIV approach for delivering volumetric measurements. By rigidly translating a stereoscopic PIV system, larger volumes may be 
measured than are achievable with large depth of field techniques, such as tomographic PIV, PTV or scanned PIV. The use of translating stereoscopic PIV for volumetric measurements is further advantageous for measurements performed on complex geometries. The number of views required to deliver the measurement is reduced, simplifying optical access. The shallow depth of field furthermore permits measurements close to highly complex geometric features. This is not without penalty, however. The uncertainties of the measurements performed are high, compared to those typically reported for stereoscopic measurements and only single-point statistics are recovered.

The technique has been demonstrated by performing volumetric measurements on an unmodified fully annular RQL combustion system from a large civil gas turbine. This was studied, unfuelled, at atmospheric conditions, with engine representative boundary conditions provided by a bespoke test facility. 3D3C measurements on unmodified geometries of this complexity are uncommon, due to the challenges associated with optical access.

As the combustor is not fuelled and therefore operated without combustion, the representativeness of the measurements to the engine environment has been evaluated. The fuel injector gas flows are associated with significant heat release, acceleration and the isothermal analogue is therefore unrepresentative of operation at engine conditions. The measured flows through the fuel injector have therefore only been described in terms of the structural errors apparent, due to the measurements being performed close to the combustion system geometry.

The results presented have instead focussed on the dynamics of dilution ports. These are crucial for the operation of RQL combustion systems, setting the stoichiometry throughout the combustor, defining recirculation times and controlling mixing within the combustor as well as defining the velocity/temperature profiles delivered to the turbine. The analysis performed indicated that the isothermal experiment was likely to result in higher momentum ratios for the port jets than would be present in the engine environment. However, the design of the combustor tested was such that the port flows were delivered in the gross overpenetration regime. In this regime, the ports are delivered with more momentum than is required to impinge.

Semi-quantitative data have therefore been presented to demonstrate the benefits of a volumetric measurement by visualising the mass transport processes occurring within the combustor. The primary port jets were observed to perform variably, depending upon their circumferential location within the combustor. Jets located in-line with the fuel injector were shown to penetrate the combustor flow, with inner and outer port jets impinging. The primary ports located out of line with the fuel injector, on the sector boundaries, were instead observed to flow directly downstream. The propagation of these jet flows downstream was attributed to external aerodynamics, which define the boundary condition to the primary port.

The secondary jets were found to generate high levels of turbulence and suggesting increased momentum flux, compared with the primary port jets. Despite this, some circumferential distribution of the impingement process performed was identified, with the secondary jets deflected towards the fuel injector centreline by out-of-line primary ports flowing directly downstream.

Acknowledgements The authors wish to thank Innovate UK and the Aerospace Technology Institute for financially supporting the development of the technique deployed here. There were two stages to this under Project Numbers 110121 and 113089. Rolls-Royce plc. is also thanked for funding the measurements performed. Finally, the authors wish to acknowledge Dr Stephen Harding for his continuing guidance and technical support.

Open Access This article is licensed under a Creative Commons Attribution 4.0 International License, which permits use, sharing, adaptation, distribution and reproduction in any medium or format, as long as you give appropriate credit to the original author(s) and the source, provide a link to the Creative Commons licence, and indicate if changes were made. The images or other third party material in this article are included in the article's Creative Commons licence, unless indicated otherwise in a credit line to the material. If material is not included in the article's Creative Commons licence and your intended use is not permitted by statutory regulation or exceeds the permitted use, you will need to obtain permission directly from the copyright holder. To view a copy of this licence, visit http://creativecommons.org/licenses/by/4.0/.

\section{References}

Bhattacharya S, Charonko JJ, Vlachos PP (2016) Stereo-particle image velocimetry uncertainty quantification. Meas Sci Technol 28:15301. https://doi.org/10.1088/1361-6501/28/1/015301

Brücker C (1997) 3D scanning PIV applied to an air flow in a motored engine using digital high-speed video. Meas Sci Technol 8:1480

Cha CM, Hong S, Ireland PT, Denman P, Savarianandam V (2012) Experimental and numerical investigation of combustor-turbine interaction using an isothermal, nonreacting tracer. J Eng Gas Turbines Power 134:81501. https://doi.org/10.1115/1.4005815

Denman PA (2002) Aerodynamic evaluation of double annular combustion systems. In: ASME turbo expo 2002: power for land, sea, and air, pp 749-757

Dhopade P, Denman P, Ireland P, Ravikanti M (2017) Experimental and numerical investigation of the effect of compressor OGV profile on combustor exit measurements using an isothermal, nonreacting tracer. In: 12th European conference on turbomachinery fluid dynamics \& thermodynamics. Euroturbo

Feitelberg AS, Lacey MA et al (1998) The GE rich-quench-lean gas turbine combustor. J Eng Gas Turbines Power 120:502-508. https ://doi.org/10.1115/1.2818173

Fishenden CR, Stevens SJ (1977) Performance of annular combustordump diffusers. J Aircr 14:60-67

Ford CL, Carrotte JF, Walker AD (2012) The impact of compressor exit conditions on fuel injector flows. J Eng Gas Turbines Power 134:111504. https://doi.org/10.1115/1.4007025 
Gnirß M, Tropea C (2008) Simultaneous PIV and concentration measurements in a gas-turbine combustor model. Exp Fluids 45:643656. https://doi.org/10.1007/s00348-008-0518-0

Grant I (1997) Particle image velocimetry: a review. Proc Inst Mech Eng Part C J Mech Eng Sci 211:55-76

Griffiths J (1999) Measurements of the flow field in a modern gas turbine combustor. Aeronautical and Automotive Engineering, Loughborough University, Loughborough

Heitor MV, Whitelaw JH (1986) Velocity, temperature, and species characteristics of the flow in a gas-turbine combustor. Combust Flame 64:1-32. https://doi.org/10.1016/0010-2180(86)90095-7

Herbon J, Aicholtz J, Hsieh S-Y, Viars P, Birmaher S, Brown D, Patel N, Carper D, Cooper C, Fitzgerald R (2017) N+2 advanced low NOx combustor technology final report

Holdeman JD (1993) Mixing of multiple jets with a confined subsonic crossflow. Prog Energy Combust Sci 19:31-70

Holdeman JD, Liscinsky DS, Oechsle VL, Samuelsen GS, Smith CE (1997) Mixing of multiple jets with a confined subsonic crossflow: part I—cylindrical duct. J Eng Gas Turbines Power 199(4):852862. https://doi.org/10.1115/1.2817065

Holdeman JD, Liscinsky DS, Bain DB (1999) Mixing of multiple jets with a confined subsonic crossflow: part II-Opposed rows of orifices in rectangular ducts. J Eng Gas Turbines Power 121:551-562

Holdemann JD, Chang CT (2008) Mixing of multiple jets with a confined subsonic crossflow: part III-the effects of air preheat and number of orifices on flow and emissions in an RQL mixing section. NASA Technical Report. TM-2008-215151. https://ntrs.nasa. gov/archive/nasa/casi.ntrs.nasa.gov/20080015508.pdf

Lefebvre AH, Ballal DR (2010) turbine combustion, Alternative fuels and emissions. Taylor \& Francis Group, Cambridge

McKinney R, Cheung A, Sowa W, Sepulveda D (2007) The Pratt \& Whitney TALON X low emissions combustor: revolutionary results with evolutionary technology. In: 45th AIAA aerospace sciences meeting and exhibit, p 386

Mehta RD, Bradshaw P (1979) Design rules for small low speed wind tunnels. Aeronaut J 83:443-453

Meier W, Boxx I, Stöhr M, Carter CD (2010) Laser-based investigations in gas turbine model combustors. Exp Fluids 49:865-882. https://doi.org/10.1007/s00348-010-0889-x

Ragni D, Schrijer F, Van Oudheusden BW, Scarano F (2011) Particle tracer response across shocks measured by PIV. Exp Fluids 50:53-64
Samuelsen GS, Brouwer J, Vardakas MA, Holdeman JD (2013) Experimental and modeling investigation of the effect of air preheat on the formation of NOx in an RQL combustor. Heat Mass Transf 49:219-231. https://doi.org/10.1007/s00231-012-1080-0

Schroll M, Doll U, Stockhausen G, Meier U, Willert C, Hassa C, Bagchi I (2017) Flow field characterization at the outlet of a lean burn single-sector combustor by laser-optical methods. J Eng Gas Turbines Power 139:11503. https://doi.org/10.1115/1.4034040

Sciacchitano A (2019) Uncertainty quantification in particle image velocimetry. Meas Sci Technol 30:92001. https://doi. org/10.1088/1361-6501/ab1db8

Sciacchitano A, Wieneke B (2016) PIV uncertainty propagation. Meas Sci Technol 27:84006

Timmerman BH, Skeen AJ, Bryanston-Cross PJ, Graves MJ (2009) Large-scale time-resolved digital particle image velocimetry (TRDPIV) for measurement of high subsonic hot coaxial jet exhaust of a gas turbine engine. Meas Sci Technol 20:74002

Vishwanath RB, Tilak PM, Chaudhuri S (2018) An experimental study of interacting swirl flows in a model gas turbine combustor. Exp Fluids 59:38. https://doi.org/10.1007/s00348-018-2495-2

Walker AD, Carrotte JF, McGuirk JJ (2008) Compressor/diffuser/combustor aerodynamic interactions in lean module combustors. J Eng Gas Turbines Power 130:11504. https://doi.org/10.1115/1.27476 46

Weber R, Dugué J (1992) Combustion accelerated swirling flows in high confinements. Prog Energy Combust Sci 18:349-367

Wieneke B (2015) PIV uncertainty quantification from correlation statistics. Meas Sci Technol 26:74002

Wieneke BFA (2017) PIV uncertainty quantification and beyond. Delft University of Technology, Delft

Wray A, Carrotte J, Wilson C (1993) The development of a large annular facility for testing gas turbine combustor diffuser systems. In: 29th joint propulsion conference and exhibit, p 2546

Publisher's Note Springer Nature remains neutral with regard to jurisdictional claims in published maps and institutional affiliations. 